\title{
Synthesis, Characterization and Photocatalytic Performance of SnS Nanofibers and SnSe Nanofibers Derived from the Electrospinning-made $\mathrm{SnO}_{2}$ Nanofibers
}

\author{
Li Cheng ${ }^{a}$, Dan Li $i^{a}$, Xiangting Dong ${ }^{a *}$, Qianli Ma ${ }^{a}$, Wensheng Yu ${ }^{a}$, Xinlu Wang ${ }^{a}$, Hui Yu ${ }^{a}$, Jinxian
}

\author{
Wang $^{a}$, Guixia Liu ${ }^{a}$
}

\author{
${ }^{a}$ Key Laboratory of Applied Chemistry and Nanotechnology at Universities of Jilin Province, \\ Changchun University of Science and Technology, 130022, Changchun, China
}

Received: April 14, 2017; Revised: August 11, 2017; Accepted: September 04, 2017

\begin{abstract}
$\mathrm{SnO}_{2}$ nanofibers were fabricated by calcination of the electrospun $\mathrm{PVP} / \mathrm{SnCl}_{4}$ composite nanofibers. For the first time, SnS nanofibers and SnSe nanofibers were successfully synthesized by doublecrucible sulfurization and selenidation methods via inheriting the morphology of $\mathrm{SnO}_{2}$ nanofibers used as precursors, respectively. X-ray diffraction (XRD) analysis shows $\mathrm{SnS}$ nanofibers and $\mathrm{SnSe}$ nanofibers are respectively pure orthorhombic phase with space group of Pbnm and $\mathrm{Cmcm}$. Scanning electron microscope (SEM) observation indicates that the diameters of $\mathrm{SnS}$ nanofibers and $\mathrm{SnSe}$ nanofibers are respectively $140.54 \pm 12.80 \mathrm{~nm}$ and $96.52 \pm 14.17 \mathrm{~nm}$ under the $95 \%$ confidence level. The photocatalytic activities of samples were studied by using rhodamine B (Rh B) as degradation agent. When $\mathrm{SnS}$ or SnSe nanofibers are employed as the photocatalysts, the respective degradation rates of $\mathrm{Rh} \mathrm{B}$ solution under the ultraviolet light irradiation after $200 \mathrm{~min}$ irradiation are $92.55 \%$ and $92.86 \%$. The photocatalytic mechanism and formation process of $\mathrm{SnS}$ and SnSe nanofibers are also provided. More importantly, this preparation technique is of universal significance to prepare other metal chalcogenides nanofibers.
\end{abstract}

Keywords: Electrospinning, SnS, SnSe, Photocatalysis, Nanofibers

\section{Introduction}

In the past few decades, metal chalcogenides have attracted considerable research interest due to their outstanding semiconducting and optical properties and potential applications in future ${ }^{1}$. Among these materials, $\mathrm{SnS}$ and SnSe are increasingly important owing to their special semiconducting properties ${ }^{2}$. SnS is a p-type semiconductor with layered orthorhombic crystal structure. The orthorhombic herzenbergite modification of $\mathrm{SnS}$ consists of double layers perpendicular to $c$ axis in which $\mathrm{Sn}$ and $\mathrm{S}$ atoms are tightly bound. The direct and indirect band gap of $\mathrm{SnS}$ were reported to be 1.2-1.5 and 1.0-1.2 eV, respectively. The narrow band gap, non-toxic nature and the interesting structure of $\mathrm{SnS}$ make it a potential candidate for solar absorber in thin film solar cells and semiconductor sensors ${ }^{3}$. Tin selenide ( $\left.\mathrm{SnSe}\right)$, as a IV-VI compound semiconductor with a band gap of about $0.9 \mathrm{eV}$, can be widely used in infrared optoelectronic devices, holographic recording systems and memory switching devices $^{4}$. Over the past several years, the synthesis of SnS and SnSe nanomaterials has been extensively explored, and considerable efforts have been made to control the size and shape of $\mathrm{SnS}$ and SnSe nanomaterials $\mathrm{s}^{5,6}$.

Presently, many methods are employed to fabricate $\mathrm{SnS}$ and SnSe nanomaterials. Typical synthetic methods include chemical bath deposition ${ }^{7-9}$, thermal evaporation ${ }^{10,11}$,

*e-mail: dongxiangting888@163.com electrodeposition ${ }^{12,13}$, spray pyrolysis technique ${ }^{14,15}$, sputtering ${ }^{16}$, etc. Different morphological SnS and SnSe nanomaterials were prepared by using the above methods, including nanoparticles ${ }^{17,18}$, nanorods ${ }^{19}$, nanoflakes ${ }^{20}$, nanofibers ${ }^{21}$, films $^{2,22}$, nanoplate ${ }^{23}$, etc. By far, no reports on the preparation of $\mathrm{SnS}$ or SnSe nanofibers are found in literatures.

Conventionally, $\mathrm{SnS}$ or $\mathrm{SnSe}$ nanomaterials are prepared via calcination of a mixture of metal oxides or thiosulfates ${ }^{7,12}$, thioure $\mathrm{a}^{18}$ and sulfur powders or selenium powders at elevated temperatures. In this way, the as-prepared nanomaterials often have irregular morphology and can not inherit the peculiar morphologies of the metal oxides precursors because sulfur powders or selenium powders will melt and destroy the morphologies of the metal oxides. Hence, it is difficult to obtain metal chalcogenides nanofibers via direct solid-state reaction using metal oxides nanofibers as precursors. In order to solve this problem, a double-crucible method is proposed and used to retain the morphology of $\mathrm{SnS}$ or $\mathrm{SnSe}$ nanofibers using $\mathrm{SnO}_{2}$ nanofibers as precursors. Double-crucible technique has been proved to be an efficient, convenient and simple way to fabricate nanofibers, nanobelts and hollow nanofibers ${ }^{24}$. Meanwhile, electrospinning is a promising, straightforward and convenient way to prepare one-dimensional (1D) nanomaterials ${ }^{25-27}$ with diameters ranging from tens of nanometers up to micrometers owing to its easy control and low cost, including nanowires ${ }^{28}$, nanobelts ${ }^{29-31}$, core-shell structured nanofibers ${ }^{32-34}$, nanofibers ${ }^{35,36}$, nanosheets ${ }^{37-39}$ 
core-shell structured nanotubes ${ }^{40,41}$, etc. Nevertheless, the fabrication of SnS or SnSe nanofibers via electrospinning combined with a double-crucible technique is not reported. Hence, fabrication of $\mathrm{SnS}$ or $\mathrm{SnSe}$ nanofibers remains a challenging and meaningful subject of study.

In this work, $\mathrm{PVP} / \mathrm{SnCl}_{4}$ composite nanofibers were fabricated by electrospinning, and $\mathrm{SnO}_{2}$ nanofibers were prepared through calcining the as-obtained composite nanofibers at $450{ }^{\circ} \mathrm{C}$. For the first time, $\mathrm{SnS}$ or $\mathrm{SnSe}$ nanofibers were synthesized by a double-crucible technique we newly proposed via inheriting the morphology of $\mathrm{SnO}_{2}$ nanofibers. The samples were systematically characterized. The morphology, structure and photocatalytic properties of the resulting samples were investigated in detail, and the formation mechanisms of $\mathrm{SnS}$ and $\mathrm{SnSe}$ nanofibers were also presented.

\section{Experimental Sections}

\subsection{Chemicals}

Polyvinyl pyrrolidone (K90, Mr=90000, AR), N,Ndimethylformamide (DMF, AR), sulfur powders and selenium powders were purchased from Tianjin Bodi Chemical Co., Ltd. $\mathrm{SnCl}_{4} \cdot 5 \mathrm{H}_{2} \mathrm{O}$ was bought from China Pharmaceutical Group Shanghai Chemical Reagent Company. Distilled water was homemade.

\subsection{Preparation of $\mathrm{PVP} / \mathrm{SnCl}_{4}$ composite nanofibers via electrospinning}

$1.00 \mathrm{~g}$ of $\mathrm{SnCl}_{4} \cdot 5 \mathrm{H}_{2} \mathrm{O}$ was dissolved in $7.60 \mathrm{~g}$ of DMF, and then $1.40 \mathrm{~g}$ of PVP was added into the above solution under magnetic stirring for $8 \mathrm{~h}$ to form homogeneous transparent spinning solution. In the spinning solution, the mass ratios of $\mathrm{PVP}, \mathrm{SnCl}_{4}$ and DMF were equal to 14:10:76. Subsequently, the spinning solution was electrospun at room temperature using ordinary electrospinning setup under a positive high voltage of $13 \mathrm{kV}$, the distance between the capillary tip and the collector was fixed to $15 \mathrm{~cm}$, and relative humidity was $20 \%-30 \%$. With the evaporation of DMF, a dense web of $\mathrm{PVP} / \mathrm{SnCl}_{4}$ composite nanofibers was formed on the collector.

\subsection{Synthesis of $\mathrm{SnO}_{2}$ nanofibers}

The above $\mathrm{PVP} / \mathrm{SnCl}_{4}$ composite nanofibers were calcined at $450{ }^{\circ} \mathrm{C}$ for $3 \mathrm{~h}$ with a heating rate of $1{ }^{\circ} \mathrm{C} \cdot \mathrm{min}^{-1}$. Then the calcination temperature was decreased to $200{ }^{\circ} \mathrm{C}$ at a rate of $1^{\circ} \mathrm{C} \cdot \mathrm{min}^{-1}$. Finally, samples were naturally cooled down to room temperature and $\mathrm{SnO}_{2}$ nanofibers were obtained.

\subsection{Fabrication of SnS nanofibers by a double- crucible sulfurization method}

$2.00 \mathrm{~g}$ of sulfur powders were loaded into a small crucible, and then $3.00 \mathrm{~g}$ of carbon rods and $0.20 \mathrm{~g}$ of $\mathrm{SnO}_{2}$ nanofibers were subsequently put into it. The small crucible was placed into a big crucible. Next, $2.00 \mathrm{~g}$ of sulfur powders were loaded into the space between the two crucibles, and then the big crucible was covered with its lid. We call this process a double-crucible method. Finally, the crucibles were heated to $800{ }^{\circ} \mathrm{C}$ with a heating rate of $5^{\circ} \mathrm{C} \cdot \mathrm{min}^{-1}$ and remained for $4 \mathrm{~h}$, then the temperature was decreased to $200^{\circ} \mathrm{C}$ at a cooling rate of $2{ }^{\circ} \mathrm{C} \cdot \mathrm{min}^{-1}$, followed by natural cooling down to ambient temperature. In the sulfurization process, Ar gas is used as shielding gas. Thus, $\mathrm{SnS}$ nanofibers were acquired.

\subsection{Preparation of SnSe nanofibers via a double- crucible selenidation method}

The procedure was the same as the sulfurization process, except that $5.00 \mathrm{~g}$ of selenium powders was used instead of sulfur powders and the selenidation reaction was conducted at $700^{\circ} \mathrm{C}$ for $3 \mathrm{~h}$.

\subsection{Characterization methods}

$\mathrm{X}$-ray diffraction (XRD) analysis was performed using a Rigaku D/max-RAX-ray diffractometer with $\mathrm{Cu}$ k $\alpha$ radiation of $0.15418 \mathrm{~nm}$. The size and morphology of the products were investigated by an XL-30 field emission scanning electron microscope (SEM) made by FEI Company. The purity of the products was examined by OXFORD ISIS300 energy dispersive X-ray spectrometer (EDS) attached to the SEM. The histograms of diameters distribution were drawn by Image-Pro-Plus 6.0 and origin 8.5 softwares. All the determinations were performed at room temperature.

\subsection{Evaluation of photocatalytic performance}

In a typical photocatalytic reaction, $5 \mathrm{~mL}$ of $0.1 \mathrm{~g} \cdot \mathrm{L}^{-1}$ $\mathrm{Rh} B$ solution was added into $95 \mathrm{~mL}$ of distilled water, then $0.05 \mathrm{~g}$ of the as-prepared $\mathrm{SnS}$ and $\mathrm{SnSe}$ nanofibers were dispersed into the above aqueous solution of $\mathrm{Rh} B$ and the solution was stirred for $2 \mathrm{~h}$ in the dark to reach adsorptiondesorption equilibrium. Then the solution was directly exposed under the ultraviolet light $(500 \mathrm{~W}$ ultraviolet lamp with main emission wavelength of $365 \mathrm{~nm}$ ) at an irradiation distance $20 \mathrm{~cm}$ with stirring to trigger decomposition of the Rh B molecules. In a 20-minute interval, $4 \mathrm{~mL}$ solution was sampled and centrifuged to remove the photocatalyst samples. The concentration of $\mathrm{Rh} B$ solution was analyzed. The degradation rate of $\mathrm{Rh} B$ was estimated on the basis of the following formula:

$$
\mathrm{D} \%=\left[\left(A_{0}-A_{t}\right) / A_{0}\right] \times 100 \%
$$

where $\mathrm{A}_{0}$ was the absorbance of $\mathrm{Rh} \mathrm{B}$ in the dark and $A_{t}$ was the absorbance of $\mathrm{Rh} B$ at given time intervals after irradiation, $\mathrm{D}$ was the degradation rate of the $\mathrm{Rh} \mathrm{B}$. 


\section{Results and Discussion}

\subsection{XRD analysis}

Figure 1a shows the XRD patterns of $\mathrm{SnO}_{2}$ nanofibers. All the diffraction peaks are highly consistent with those of the pure tetragonal-phase of $\mathrm{SnO}_{2}$ (PDF\#88-0287) with space group of $\mathrm{P} 42 / \mathrm{mnm}$. Obvious diffraction peaks are located near $2 \theta=26.2^{\circ}(110), 33.9^{\circ}(101), 37.9^{\circ}(200), 51.9^{\circ}$ (211), 54.8 $(220), 62.9^{\circ}(112), 65.9^{\circ}$ (311), $78.8^{\circ}$ (321), $83.9^{\circ}$ (222), etc. No diffraction peaks of any other phases or impurities are also detected, indicating that pure-phase $\mathrm{SnO}_{2}$ nanofibers are successfully prepared.

Figure $1 \mathrm{~b}$ reveals the XRD patterns of $\mathrm{SnS}$ nanofibers, and the diffraction peaks can be easily indexed to those of the pure orthorhombic phase of SnS (PDF\#75-0925), and the space group is Pbnm. Obvious diffraction peaks are situated near $2 \theta=25.9^{\circ}(201), 25.6^{\circ}(210), 31.8^{\circ}(111), 37.0^{\circ}(311)$, $44.8^{\circ}(411), 51.2^{\circ}(121), 66.2^{\circ}(800), 75.6^{\circ}(811), 84.2^{\circ}$ (820), etc. No peaks of any other phases or impurities are also detected, implying that crystalline $\mathrm{SnS}$ is acquired.

Figure 1c manifests shows the XRD patterns of $\mathrm{SnSe}$ nanofibers. Its reflection peaks can be readily indexed to those of the pure orthorhombic phase of SnSe (PDF\#53-0527), and the space group is $\mathrm{Cmcm}$. Obvious diffraction peaks are located near $2 \theta=15.5^{\circ}(002), 26.5^{\circ}(012), 28.5^{\circ}(110), 31.0^{\circ}$ (004), 38.0 $0^{\circ}(014), 43.2^{\circ}$ (202), $44.2^{\circ}$ (115), $47.6^{\circ}$ (022), $49.6^{\circ}(115)$, etc. No peaks of any other phases or impurities are detected, indicating that crystalline $\mathrm{SnSe}$ is obtained.

\subsection{Morphology observation}

The morphologies of the products are characterized by scanning electron microscope (SEM). Figure 2 manifests the representative SEM images of $\mathrm{PVP} / \mathrm{SnCl}_{4}$ composite nanofibers, $\mathrm{SnO}_{2}$ nanofibers, $\mathrm{SnS}$ nanofibers and $\mathrm{SnSe}$ nanofibers. From Figure 2a, it can be noticed that $\mathrm{PVP} / \mathrm{SnCl}_{4}$ composite nanofibers have smooth surface and uniform diameter. After calcination at $450^{\circ} \mathrm{C}$, the diameter of $\mathrm{SnO}_{2}$ nanofibers greatly decreases due to loss of the PVP and associated organic components, as revealed in Figure $2 b$. $\mathrm{SnS}$ nanofibers and $\mathrm{SnSe}$ nanofibers have relatively rough surface, as seen in Figure 2c and 2d. From these analyses, we can safely conclude that the double-crucible technique we proposed here can remain the morphology of the $\mathrm{SnO}_{2}$ precursor nanofibers.

Histograms of diameters of these fibers are indicated in Figure 3. Under the $95 \%$ confidence level, the diameters of fibers analyzed by Shapiro-Wilk method are normal distribution. The diameters of PVP/ $\mathrm{SnCl}_{4}$ composite nanofibers, $\mathrm{SnO}_{2}$ nanofibers, $\mathrm{SnS}$ nanofibers and $\mathrm{SnSe}$ nanofibers are $255.55 \pm 23.73 \mathrm{~nm}, 63.56 \pm 6.74 \mathrm{~nm}, 140.54 \pm 12.80 \mathrm{~nm}$ and $96.52 \pm 14.17 \mathrm{~nm}$, respectively.

Figure 4 demonstrates the EDS spectra of $\mathrm{PVP} / \mathrm{SnCl}_{4}$ composite nanofibers, $\mathrm{SnO}_{2}$ nanofibers, $\mathrm{SnS}$ nanofibers and SnSe nanofibers. EDS spectra analysis shows that $\mathrm{C}, \mathrm{N}$, $\mathrm{O}, \mathrm{Sn}, \mathrm{Cl}$ are the main elements in $\mathrm{PVP} / \mathrm{SnCl}_{4}$ composite nanofibers and the presence of $\mathrm{Sn}, \mathrm{O}$ corresponds to $\mathrm{SnO}_{2}$ nanofibers, as seen in Figure $4 \mathrm{a}$ and $4 \mathrm{~b}$. Sn, $\mathrm{S}$ are the main elements in $\mathrm{SnS}$ nanofibers and the presence of $\mathrm{Sn}, \mathrm{Se}$ corresponds to SnSe nanofibers, as indicated in Figure 4c and $4 \mathrm{~d}, \mathrm{C}$ exists in $\mathrm{SnS}$ and $\mathrm{SnSe}$ nanofibers due to carbon rods loaded into the small crucible during the sulfurization and selenidation process, Pt comes from the conductive films coated on the samples for SEM analysis, and the $\mathrm{O}$ is owing to absorbed oxygen.

\subsection{Photocatalytic properties}

The photocatalytic activity of the $\mathrm{SnO}_{2}$ nanofibers, $\mathrm{SnS}$ nanofibers and SnSe nanofibers were evaluated by the degradation of Rh B solution under ultraviolet irradiation, as seen in Figure 5. Figure 5 displays the degradation curves of $\mathrm{Rh} \mathrm{B}$ solution and first-order reaction kinetics curves. The degradation rate of $\mathrm{Rh} B$ solution reaches $85.90 \%$ using $\mathrm{SnO}_{2}$ nanofibers after $180 \mathrm{~min}$ irradiation. While $\mathrm{SnS}$ nanofibers or SnSe nanofibers are employed as the photocatalysts, the respective degradation rates of $\mathrm{Rh} B$ solution after $200 \mathrm{~min}$
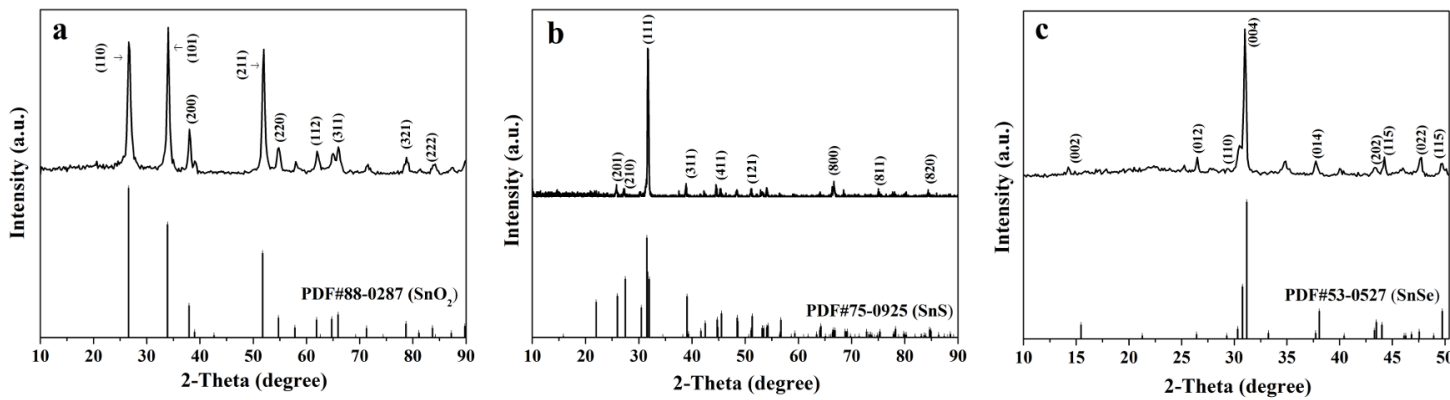

Figure 1. $\mathrm{XRD}$ patterns of $\mathrm{SnO}_{2}$ nanofibers (a), $\mathrm{SnS}$ nanofibers (b) and $\mathrm{SnSe}$ nanofibers (c) with PDF standard cards of $\mathrm{SnO}_{2}, \mathrm{SnS}$ and $\mathrm{SnSe}$. 
irradiation are $92.55 \%$ and $92.86 \%$. Degradation of Rh B solution accords with the first-order reaction kinetics equation:

$$
\ln \left(\frac{C}{C_{0}}\right)=-K\left(t-t_{0}\right)
$$

where $\mathrm{C}_{0}$ is the initial concentration of $\mathrm{Rh} B$ solution, $\mathrm{C}$ is the concentration of $\mathrm{Rh} \mathrm{B}$ solution at given time intervals after irradiation, $\mathrm{K}$ is the rate constant, $\mathrm{t}_{0}$ is the initial irradiation time and $\mathrm{t}$ is the irradiation time. The rate constant $\mathrm{K}$ of $\mathrm{SnO}_{2}$ nanofibers, $\mathrm{SnS}$ nanofibers and SnSe nanofibers are $\mathrm{K}_{1}=0.00988 \mathrm{~s}^{-1}, \mathrm{~K}_{2}=0.01336 \mathrm{~s}^{-1}$ and $\mathrm{K}_{3}=0.01357 \mathrm{~s}^{-1}$, respectively.

\subsection{Possible mechanism of the ultraviolet- induced photodegradation of $R h B$}

Based on the above results, a possible photocatalytic mechanism is indicated in Figure 6. As shown in Figure 6, $\mathrm{SnS}$ nanofibers and $\mathrm{SnSe}$ nanofibers with narrow band gap energy ( $c a$. $1.01 \mathrm{eV}$ and $0.90 \mathrm{eV}$ ) could be easily excited by ultraviolet light to generate photoelectrons and holes. Then the photo-generated electrons ( $\mathrm{e}^{-}$) probably react with dissolved oxygen molecules to yield super oxide radical anions $\mathrm{O}_{2} \cdot$, which on protonation forms the hydroperoxy $\mathrm{HO}_{2} \cdot$ and the hydroxyl radical $\mathrm{OH}^{-}$. Simultaneously, the holes $\left(\mathrm{h}^{+}\right)$could oxidize $\mathrm{OH}^{-}$and $\mathrm{H}_{2} \mathrm{O}$ to generate $\mathrm{OH} \cdot \mathrm{HO}_{2} \cdot$ and $\mathrm{OH} \cdot$ which are strong oxidizing agent could make $\mathrm{C}-\mathrm{C}, \mathrm{C}-\mathrm{O}$ and $\mathrm{C}-\mathrm{H}$ in $\mathrm{Rh} \mathrm{B}$ molecule rupture to form harmless $\mathrm{CO}_{2}$ and $\mathrm{H}_{2} \mathrm{O}$.

\section{Formation Mechanisms for SnS Nanofibers and SnSe Nanofibers}

On the basis of above analytic of results, we propose the formation mechanisms for $\mathrm{SnS}$ nanofibers and $\mathrm{SnSe}$ nanofibers, as shown in Figure 7. PVP and $\mathrm{SnCl}_{4}$ were mixed with $\mathrm{DMF}$ to form spinning solution with certain viscosity. Then, $\mathrm{PVP} / \mathrm{SnCl}_{4}$ composite nanofibers were obtained via electrospinning. During calcination process, PVP chain was broken and volatilized. With the increase in calcination temperature, $\mathrm{Sn}^{4+}$ was oxidized to form $\mathrm{SnO}_{2}$ crystallites, many crystallites were combined into nanoparticles, then some nanoparticles were mutually connected to generate $\mathrm{SnO}_{2}$ nanofibers. PVP acted as template during the formation of $\mathrm{SnO}_{2}$ nanofibers. It was found from experiments that the average molecular weight and content of PVP in the spinning solution played important roles in the formation of $\mathrm{SnO}_{2}$ nanofibers. Next, $\mathrm{SnO}_{2}$ nanofibers were sulfurized and selenided using $\mathrm{S}$ and Se powders as sulfurizing and
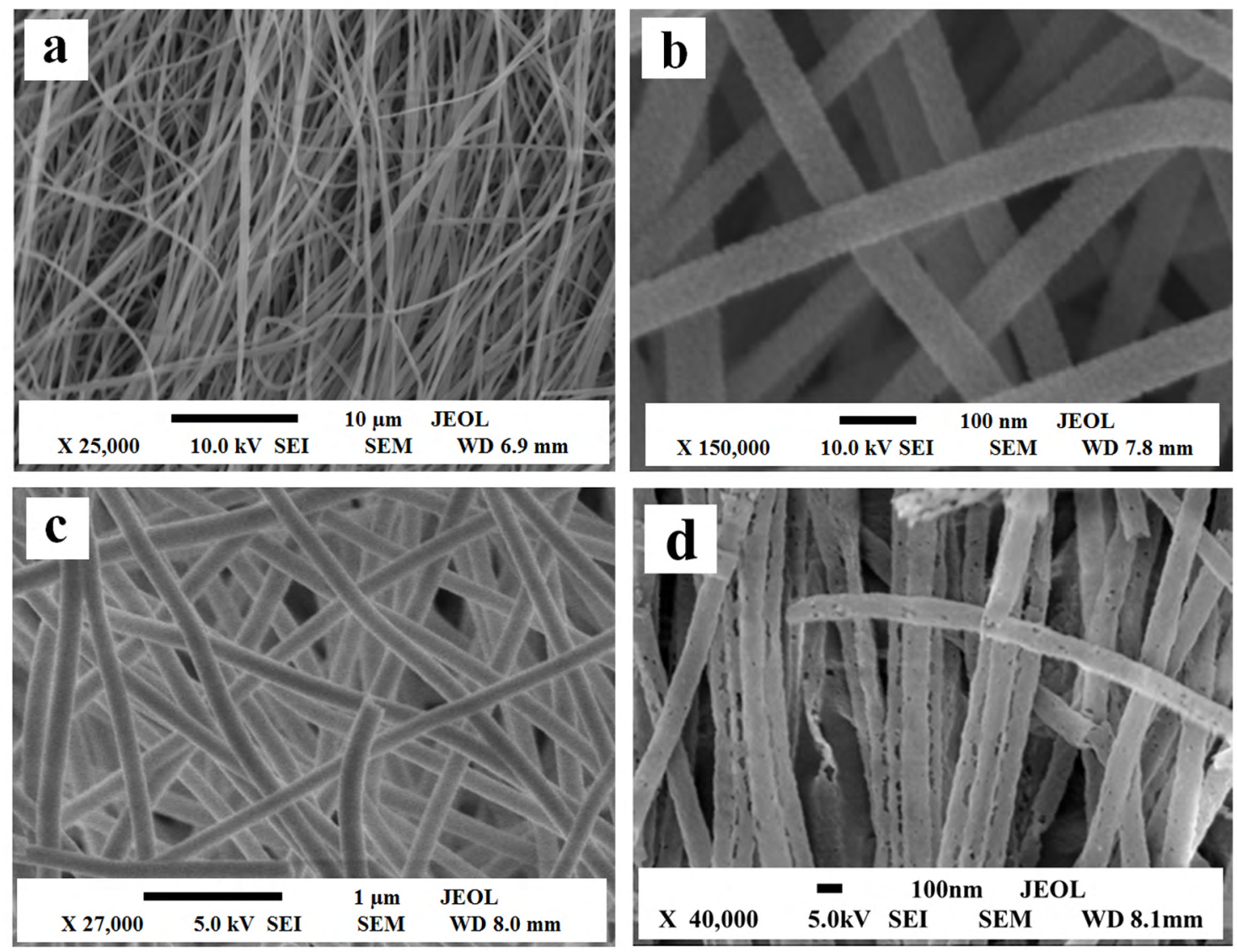

Figure 2. $\mathrm{SEM}$ images of $\mathrm{PVP} / \mathrm{SnCl}_{4}$ composite nanofibers (a), $\mathrm{SnO}_{2}$ nanofibers (b), $\mathrm{SnS}$ nanofibers (c) and SnSe nanofibers (d). 

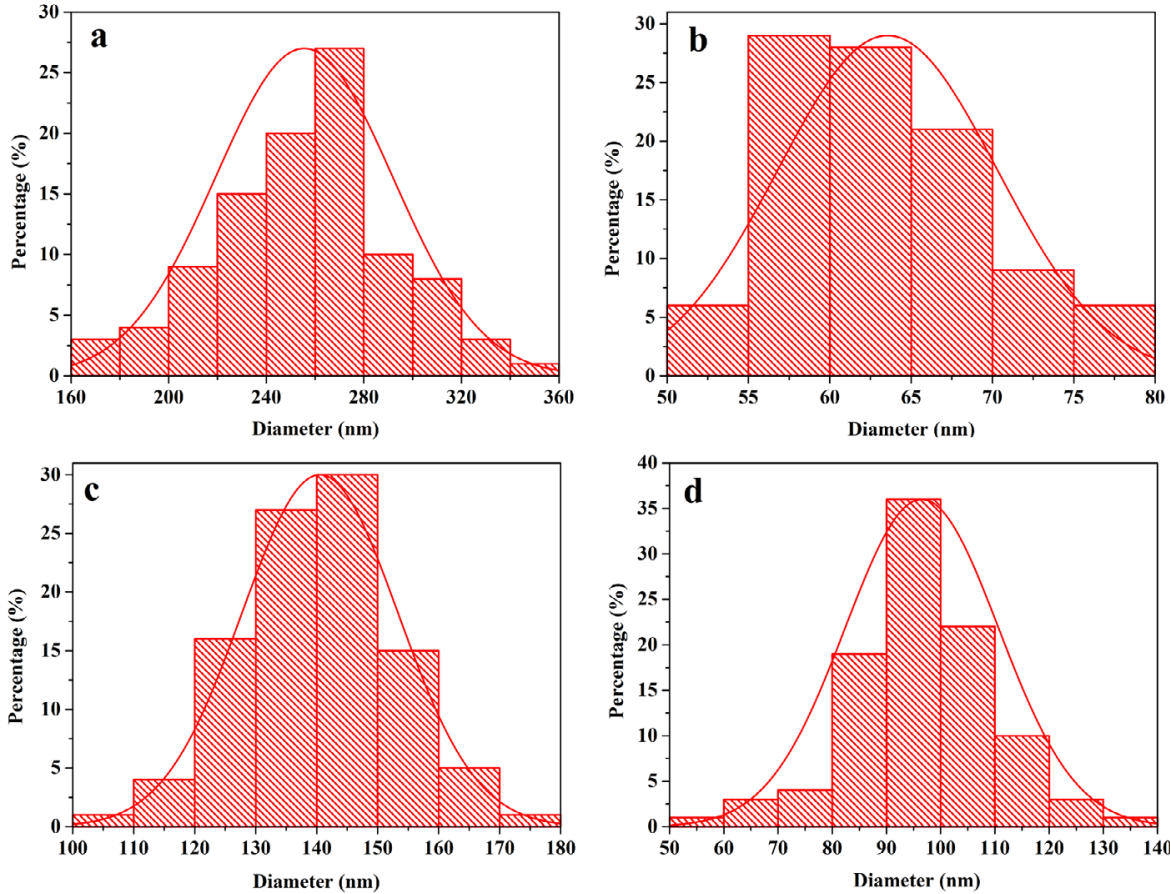

Figure 3. Histograms of diameters of $\mathrm{PVP} / \mathrm{SnCl}_{4}$ composite nanofibers (a), $\mathrm{SnO}_{2}$ nanofibers (b), $\mathrm{SnS}$ nanofibers (c) and SnSe nanofibers (d).
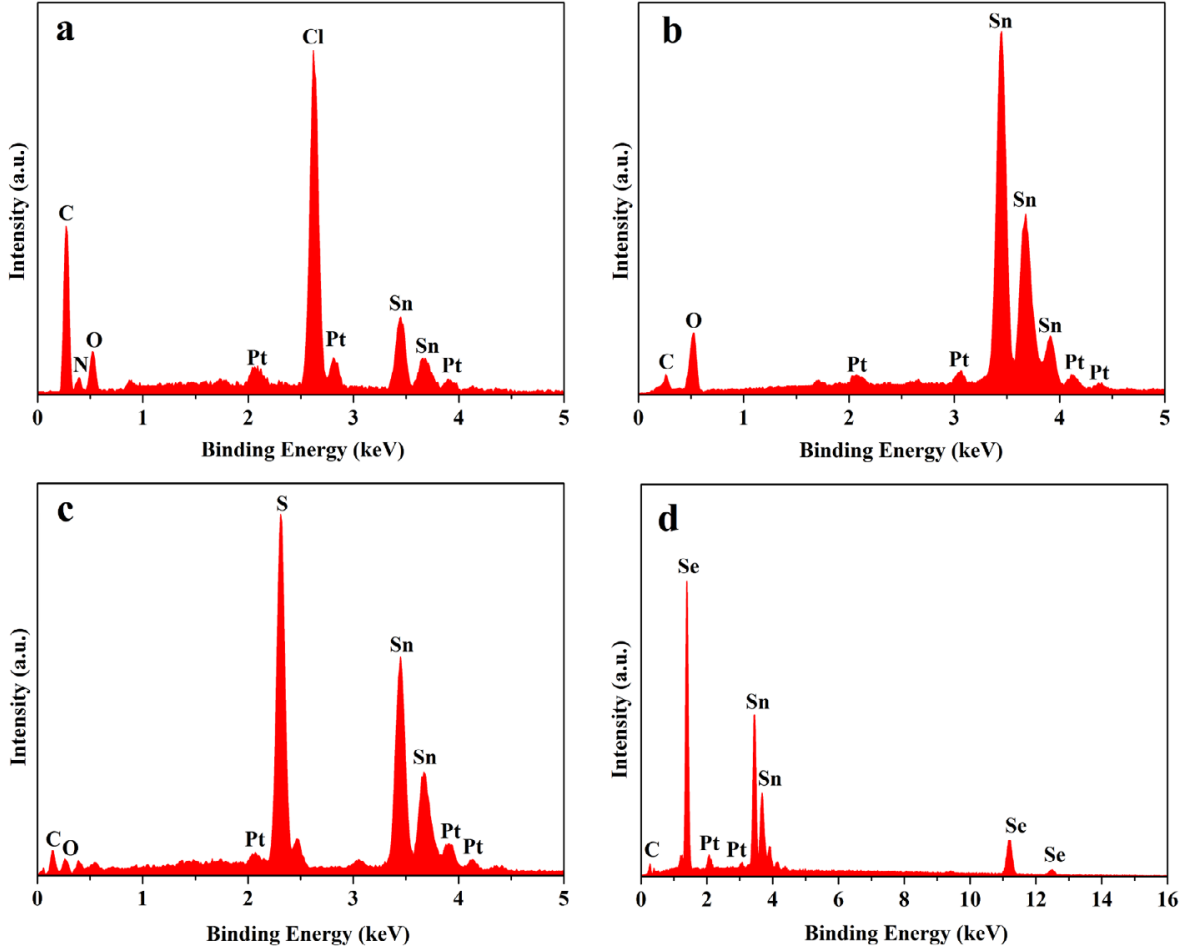

Figure 4. EDS spectra of $\mathrm{PVP} / \mathrm{SnCl}_{4}$ composite nanofibers (a), $\mathrm{SnO}_{2}$ nanofibers (b), $\mathrm{SnS}$ nanofibers (c) and SnSe nanofibers (d). 

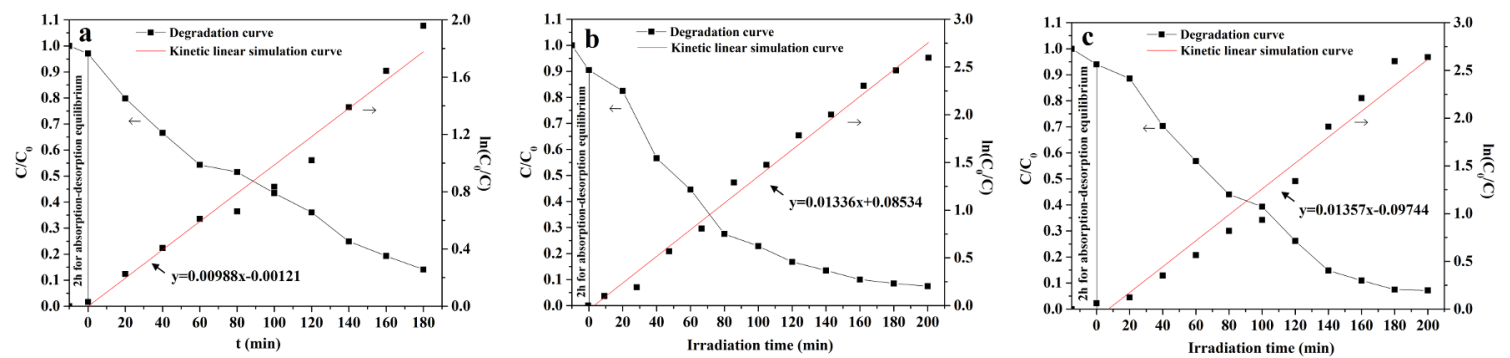

Figure 5. Variation of degradation curves of $\mathrm{Rh} \mathrm{B}$ with irradiation time over $\mathrm{SnO}_{2}$ nanofibers (a), $\mathrm{SnS}$ nanofibers (b) and $\mathrm{SnSe}$ nanofibers (c).

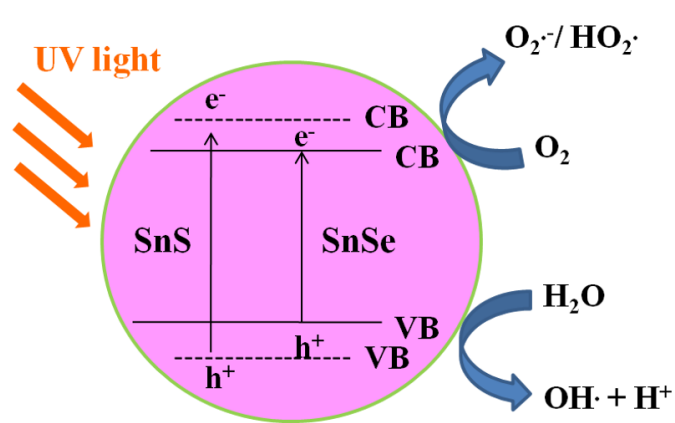

Figure 6. Possible mechanism of the ultraviolet-induced photodegradation of $\mathrm{Rh} \mathrm{B}$ with $\mathrm{SnS}$ nanofibers and SnSe nanofibers.

seleniding agents. In the process, $\mathrm{S}$ or Se reacted with $\mathrm{SnO}_{2}$ nanofibers to produce $\mathrm{SnS}$ nanofibers or $\mathrm{SnSe}$ nanofibers. During the process, $\mathrm{S}$ or Se powders and $\mathrm{SnO}_{2}$ nanofibers were separated by the carbon rods, which prevented $\mathrm{SnO}_{2}$ nanofibers from morphology damage. If $\mathrm{SnO}_{2}$ nanofibers directly mix with $\mathrm{S}$ or Se powders, melted $\mathrm{S}$ or Se will cut the $\mathrm{SnO}_{2}$ nanofibers into pieces, as a result, the morphology of $\mathrm{SnO}_{2}$ nanofibers cannot be retained. Carbon rods played an important role in the reduction via combination with $\mathrm{O}_{2}$ to produce $\mathrm{CO}$, which reacted with oxygen species of $\mathrm{SnO}_{2}$ to give $\mathrm{CO}_{2}$ in the heating process. The double-crucible method we proposed here is actually a solid-gas reaction, which has been proved to be an important method, not only can retain the morphology of $\mathrm{SnO}_{2}$ nanofibers, but also can fabricate $\mathrm{SnS}$ nanofibers and SnSe nanofibers with pure phase at relatively low temperature. Reaction schemes for formation of SnS nanofibers or SnSe nanofibers proceeded as follows:

$$
\mathrm{PVP} / \mathrm{SnCl}_{4}+\mathrm{O}_{2} \stackrel{450^{\circ} \mathrm{C}}{\longrightarrow} \mathrm{CO}_{2}+\mathrm{H}_{2} \mathrm{O}+\mathrm{HCl}+\mathrm{SnO}_{2}
$$

$$
\mathrm{SnO}_{2}+\mathrm{S}+2 \mathrm{CO} \stackrel{800^{\circ} \mathrm{C}}{\longrightarrow} \mathrm{SnS}+2 \mathrm{CO}_{2}
$$

$$
\mathrm{SnO}_{2}+\mathrm{Se}+2 \mathrm{CO} \stackrel{{ }^{700^{\circ} \mathrm{C}} \longrightarrow}{\longrightarrow} \mathrm{SnSe}+2 \mathrm{CO}_{2}
$$

\section{Conclusions}

In summary, $\mathrm{SnO}_{2}$ nanofibers were fabricated by calcination of $\mathrm{PVP} / \mathrm{SnCl}_{4}$ composite nanofibers prepared via electrospinning, and pure-phase orthorhombic $\mathrm{SnS}$ nanofibers or SnSe nanofibers with space group of Pbnm or

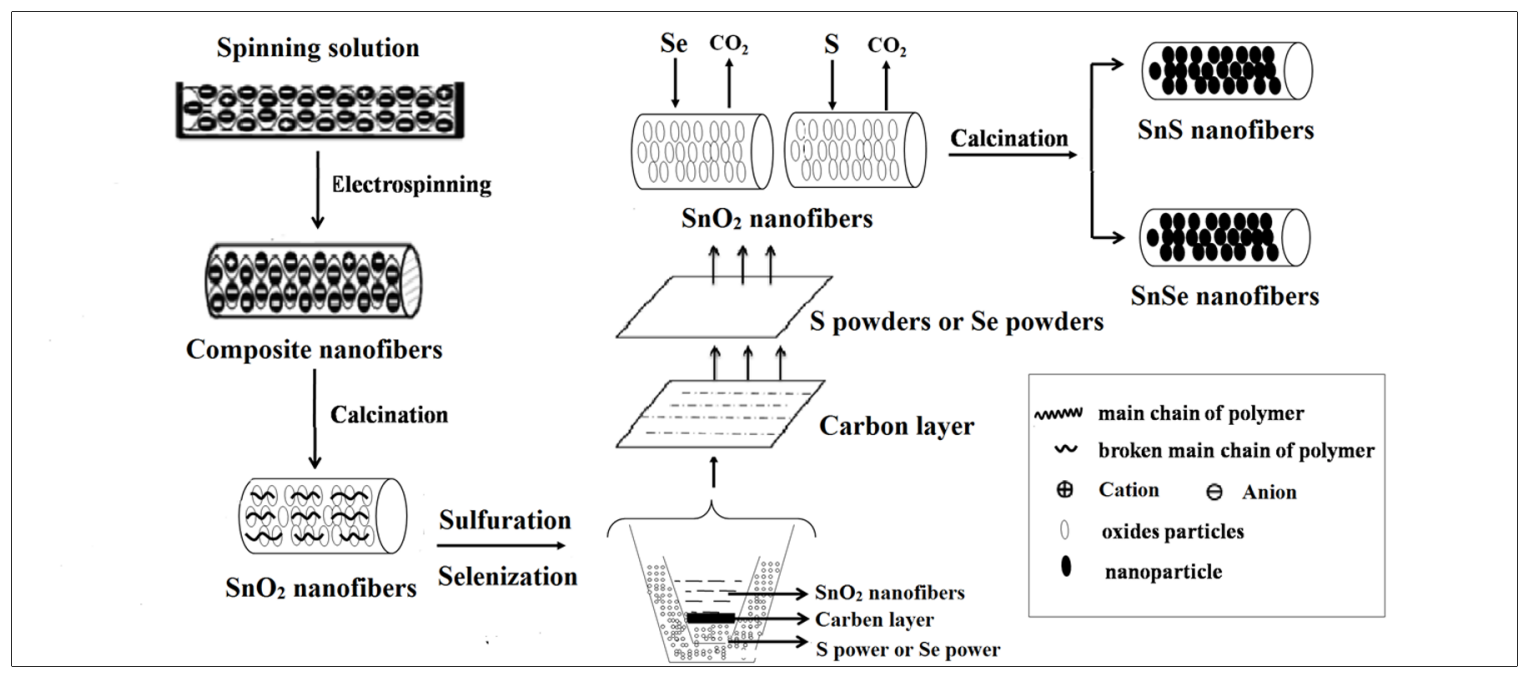

Figure 7. Formation mechanisms of $\mathrm{SnS}$ nanofibers and SnSe nanofibers. 
Cmcm were obtained by sulfuration or selenization of the as-obtained $\mathrm{SnO}_{2}$ nanofibers. The as-prepared $\mathrm{SnS}$ nanofibers and SnSe nanofibers have relatively rough surface, their diameters are respectively $140.54 \pm 12.80 \mathrm{~nm}$ and $96.52 \pm 14.17$ $\mathrm{nm}$. SnS nanofibers and SnSe nanofibers possess excellent photocatalytic performance. The double-crucible technology we proposed here is of great importance, it can be applicable to synthesize other metal chalcogenides nanostructures with various morphologies.

\section{Acknowledgments}

This work was financially supported by National Natural Science Foundation of China (51573023, 50972020), Natural Science Foundation of Jilin Province of China (20170101101JC), Industrial Technology Research and Development Project of Jilin Province Development and Reform Commission (2017C051), Science and Technology Research Planning Project of the Education Department of Jilin Province during the 13th Five-Year Plan Period (JJKH20170608KJ), Youth Foundation of Changchun University of Science and Technology (No. XQNJJ-2016-01).

\section{References}

1. Tang H, Yu JG, Zhao X. Solvothermal synthesis of novel dendritelike $\mathrm{SnS}$ particles in a mixed solvent of ethylenediamine and dodecanethiol. Journal of Alloys and Compounds. 2008;460(12):513-518.

2. Park JP, Song MY, Jung WM, Lee WY, Lee JH, Kim HG, et al. Preparation of SnS Thin Films by MOCVD Method Using Single Source Precursor, Bis(3-mercapto-1-propanethiolato) Sn(II). Bulletin of the Korean Chemical Society. 2012;33(10):33833386.

3. Zhang H, Hu C, Wang X, Xi Y, Li X. Synthesis and photosensitivity of SnS nanobelts. Journal of Alloys and Compounds. 2012;513:15 .

4. Sharma J, Singh G, Thakur A, Saini GSS, Goyal N, Tripathi SK. Preparation and characterization of SnSe nanocrystalline thin films. Journal of Optoelectronics and Advanced Materials. 2005;7(4):2085-2094.

5. Hsu KC, Wu DY, Lin PY, Fu YS, Liao JD. Molecular assessment of histopathological staging in squamous-cell carcinoma of the head and neck. Journal of Applied Polymer Science. 2015;33:132-137.

6. Nassary MM. The electrical conduction mechanisms and thermoelectric power of SnSe single crystals. Turkish Journal of Physics. 2009;33(4):201-208.

7. Gao $\mathrm{C}$, Shen H. Influence of the deposition parameters on the properties of orthorhombic $\mathrm{SnS}$ films by chemical bath deposition. Thin Solid Films. 2012;520(9):3523-3527.

8. Mukherjee A, Mitra P. Characterization of tin (II) sulphide thin film synthesized by successive chemical solution deposition. Indian Journal of Physics. 2015;89(10):1007-1012.
9. He HY, Fei J, Lu J. Rapid Chemical Bath Depositions and Properties of SnS Films. Materials and Manufacturing Processes. 2014;29(9):1044-1049.

10. Kawano Y, Chantana J, Minemoto T. Impact of growth temperature on the properties of SnS film prepared by thermal evaporation and its photovoltaic performance. Current Applied Physics. 2015;15(8):897-901.

11. Abdelrahman AE, Yunus WMM, Arof AK. Optical properties of tin sulphide $(\mathrm{SnS})$ thin film estimated from transmission spectra. Journal of Non-Crystalline Solids. 2012;358(12-13):1447-1451.

12. Mariappan R, Mahalingam T, Ponnuswamy V. Preparation and characterization of electrodeposited $\mathrm{SnS}$ thin films. Optik - International Journal for Light and Electron Optics. 2011;122(24):2216-2219.

13. Steichen M, Djemour R, Gütay L, Guillot J, Siebentritt S, Dale PJ. Direct synthesis of single-phase p-type $\mathrm{SnS}$ by electrodeposition from a dicyanamide Ionic liquid at high temperature for thin film solar cells. Journal of Physical Chemistry C. 2013;117(9):43834393.

14. Reddy NK, Reddy KTR. Preparation and characterisation of sprayed tin sulphide films grown at different precursor concentrations. Materials Chemistry and Physics. 2007;102(1):13-18.

15. Akbari T, Rozati SM. Preparation and growth of $\mathrm{SnS}$ thin film deposited by spray pyrolysis technique. Chemistry of Solid Materials. 2014;2(1):33-39.

16. Chao J, Xie Z, Duan X, Dong Y, Wang Z, Xu J, et al. Visiblelight-driven photocatalytic and photoelectrochemical properties of porous $\operatorname{SnS}_{x}(x=1,2)$ architectures. CrystEngComm. 2012;14(9):3163-3168.

17. Gou XL, Chen J, Shen PW. Synthesis, characterization and application of $\operatorname{SnS}_{x}(x=1,2)$ nanoparticles. Materials Chemistry and Physics. 2005;93(2-3):557-566.

18. Muthuvinayagam A, Viswanathan B. Hydrothermal synthesis and LPG sensing ability of SnS nanomaterial. Indian Journal of Chemistry. 2015;54A:155-160.

19. An C, Tang K, Jin Y, Liu Q, Chen X, Qian Y. Shape-selected synthesis of nanocrystalline $\mathrm{SnS}$ in different alkaline media. Journal of Crystal Growth. 2003;252(4):581-586.

20. Du M, Yin X, Gong H. Effects of triethanolamine on the morphology and phase of chemically deposited tin sulfide. Materials Letters. 2015;152:40-44.

21. Shen Z, Hu Y, Chen Y. Tin nanoparticle-loaded porous carbon nanofiber composite anodes for high current lithium-ion batteries. Journal of Power Sources. 2015;278:660-667.

22. Sun YF, Cheng H, Gao S, Sun ZH, Liu QH, Liu Q, et al. Freestanding Tin Disulfide Single-Layers Realizing Efficient Visible-Light Water Splitting. Angewandte Chemie. 2012;51(35):8727-8731.

23. Rath T, Gury L, Sánchez-Molina I, Martínez L, Haque SA. Formation of porous $\mathrm{SnS}$ nanoplate networks from solution and their application in hybrid solar cells. Chemical Communications. 2015;51(50):10198-10201.

24. Kong Q, Wang J, Dong X, Yu W, Liu G. Synthesis and luminescence properties of $\mathrm{LaOCl}: \mathrm{Eu}^{3+}$ nanostructures via the combination of electrospinning with chlorination technique. Journal of Materials Science: Materials in Electronics. 2013;24(12):4745-4756. 
25. Hou Z, Li G, Lian HZ, Lin J. One-dimensional luminescent materials derived from the electrospinning process: preparation, characteristics and application. Journal of Materials Chemistry. 2012;22(12):5254-5276.

26. Tian J, Ma Q, Dong X, Yang M, Yang Y, Wang J, et al. Flexible composite nanobelts: facile electrospinning construction, structure and color-tunable photoluminescence. Journal of Materials Science: Materials in Electronics. 2015;26(11):8413-8420.

27. Hou Z, Li C, Yang J, Lian H, Yang P, Chai R, et al. Onedimensional $\mathrm{CaWO}_{4}$ and $\mathrm{CaWO}_{4}: \mathrm{Tb}^{3+}$ nanowires and nanotubes: electrospinning preparation and luminescent properties. Journal of Materials Chemistry. 2009;19(18):2737-2746.

28. Ma Q, Wang J, Dong X, Yu W, Liu G. Flexible ribbon-shaped coaxial electrical Conductive nanocable array endowed with magnetism and photoluminescence. RSC Advances. 2015;5(4):2523-2530.

29. Han C, Ma Q, Dong X, Yu W, Wang J, Liu G. In situ synthesis of porous $\mathrm{Fe}_{3} \mathrm{O}_{4} / \mathrm{C}$ composite nanobelts with tunable magnetism, electrical conduction and highly efficient. adsorption characteristics. Journal of Materials Science: Materials in Electronics. 2015;26(4):2457-2465.

30. Liu Y, Wang JX, Dong XT, Liu GX. Fabrication of $\mathrm{Gd}_{3} \mathrm{Ga}_{5} \mathrm{O}_{12}: \mathrm{Eu}^{3+}$ Porous Luminescent Nanobelts via Electrospinning. Chemical Journal of Chinese Universities. 2010;31(7):1291-1296.

31. Xue H, Sun X, Bi J, Wang T, Han J, Ma Q, et al. Facile electrospinning construction and characteristics of coaxial nanobelts with simultaneously tunable magnetism and colortuned photoluminescence bifunctionality. Journal of Materials Science: Materials in Electronics. 2015;26(1):8774-8783.

32. Hou Z, Li C, Ma P, Cheng Z, Li X, Zhang X, et al. UpConversion Luminescent and Porous $\mathrm{NaYF}_{4}: \mathrm{Yb}^{3+}, \mathrm{Er}^{3+} @ \mathrm{SiO}_{2}$ Nanocomposite Fibers for Anti-Cancer Drug Delivery and Cell Imaging. Advanced Functional Materials. 2012;22(13):27132722 .

33. Ma Q, Wang J, Dong X, Yu W, Liu G, Xu J. Electrospinning preparation and properties of magnetic-photoluminescent bifunctional coaxial nanofibers. Journal of Materials Chemistry. 2012;22(29):14438-14442.

34. Liu Z, Sun DD, Guo P, Leckie JO. An efficient bicomponent $\mathrm{TiO}_{2} / \mathrm{SnO}_{2}$ nanofiber photocatalyst fabricated by electrospinning with a side-by-side dual spinneret method. Nano Letters. 2007;7(4):1081-1085.

35. Yang F, Ma Q, Dong X, Yu W, Wang J, Liu G. A novel scheme to obtain tunable fluorescent colors based on electrospun composite nanofibers. Journal of Materials Science: Materials in Electronics. 2015;26(1):336-344.

36. Zhou X, Ma Q, Dong X, Wang J, Yu W, Liu G. Dy ${ }^{3+}$ and $\mathrm{Eu}^{3+}$ complexes co-doped flexible composite nanofibers to achieve tunable fluorescent color. Journal of Materials Science: Materials in Electronics. 2015;26(5):3112-3118.

37. Wang K, Shao C, Li X, Zhang X, Lu N, Miao F, et al. Hierarchical heterostructures of p-type $\mathrm{BiOCl}$ nanosheets on electrospun n-type $\mathrm{TiO}_{2}$ nanofibers with enhanced photocatalytic activity. Catalysis Communications. 2015;67:6-10.

38. Wang K, Shao C, Li X, Miao F, Lu N, Liu Y. Heterojunctions of p-BiOI Nanosheets $/ \mathrm{n}-\mathrm{TiO}_{2}$ Nanofibers: Preparation and Enhanced Visible-Light Photocatalytic Activity. Materials (Basel). 2016;9(2):90.

39. Zhang Z, Shao C, Li X, Sun Y, Zhang M, Mu J, et al. Hierarchical assembly of ultrathin hexagonal $\mathrm{SnS}_{2}$ nanosheets onto electrospun $\mathrm{TiO}_{2}$ nanofibers: enhanced photocatalytic activity based on photoinduced interfacial charge transfer. Nanoscale. 2013;5(2):606-618.

40. Zhang P, Wang L, Zhang X, Shao CL, Hu J, Shao G. $\mathrm{SnO}_{2}$-core carbon-shell composite nanotubes with enhanced photocurrent and photocatalytic performance. Applied Catalysis B: Environmental. 2015;166-167:193-201.

41. Miao F, Shao C, Li X, Wang K, Lu N, Liu Y. Electrospun carbon nanofibers/carbon nanotubes/polyaniline ternary composites with enhanced electrochemical performance for flexible solid-State supercapacitors. ACS Sustainable Chemistry \& Engineering. 2016;4(3):1689-1696. 